\title{
Writing Folklore Based on Local Wisdom as an Introduction to The Archipelago Culture on Learning TISOL in Surakarta City
}

\author{
Sri Hastuti \\ Postgraduate Doctoral Program in Indonesian Language Education, Universitas Sebelas Maret \\ Surakarta \\ hastuti2005@gmail.com
}

\begin{abstract}
The purpose of this study is to describe folklore based on local wisdom as an introduction to the archipelago culture on learning Tisol in Surakarta city. The method used in this research is descriptive qualitative, observation, and interview. Folklore is spread verbally, word of mouth from parents to children or grandchildren, with the aim of giving advice, advice that is illustrated by the character of the story. Advice usually contains the values of students, moral messages, ethics and manners embraced by eastern society. As oral literature, many possibilities of folklore will disappear from the archipelago, as they leave their ancestors, native speakers of folklore. So we need a means to maintain this culture by writing it in written literary form. Folklore written in the form of book documents, has the following benefits: (1) as learning material for students of all levels of education, (2) as Indonesian Language Education student textbooks, especially in creative writing courses, (3) as Tisol learning material, (4 ) a book on cultural enrichment of the local area, (5) preservation of the archipelago culture in the field of literature.
\end{abstract}

Keywords: Folklore, Local Wisdom, Archipelago Culture, Learning TISOL

\section{PENDAHULUAN}

Indonesia sebagai Negara kepulauan memiliki keanekaragaman budaya dengan kearifanlokalnya. Salah satunya adalah cerita rakyat. Cerita rakyat adalah cerita yang disebarkan secara lisan, dari mulut ke mulut dari orang tua kepada anak cucu atau generasi penerusnya, atau tukang cerita (yang faham tentang cerita itu) kepada siapa saja (orang dewasa atau anak). Cerita rakyat biasanya disampaikan secara lisan oleh tukang cerita yang hafal alur ceritanya, itulah sebabnya cerita rakyat disebut juga sebagai sastra lisan. Cerita disampaikan oleh tukang cerita sambil duduk-duduk di suatu tempat kepada siapa saja, anak-anak dan orang dewasa [1]. Cerita rakyat diberikan untuk menyampaikan nasihat atau amanat yang berisi pesan moral, budi pekerti dan nilai kesopanan sebagai ciri budaya masyarakat tersebut. Menurut Hutomo [2], 'cerita rakyat adalah ekspresi budaya suatu masyarakat melalui bahasa tutur yang berhubungan langsung dengan berbagai aspek budaya dan susunan nilai sosial masyarakat tersebut. Dahulu cerita rakyat 
diwariskan secara turun temurun dari satu generasi berikutnya secara lisan', sedang Barone [3]mengemukakan bahwa cerita rakyat merupakan bagian dari sastra tradisional. Ceritanya pendek dan jalan cerita atau peristiwanya sering kali dengan karakter yang baik atau jahat.

Dalam perkembangannya, cerita rakyat memiliki bermacam-macam jenis seperti mite, legenda dan dongeng. Ketiga macam cerita ini oleh masyarakat kadang bertumpangtindih pengertiannya. Pengertian secara umum, mite atau yang biasa dikenal dengan istilah mitos adalah cerita berlatar belakang sejarah yang dipercaya itu ada, benar dan dianggap suci oleh masyarakat tertentu, missal mitost tentang Nyi Loro Kidul, legenda adalah cerita rakyat yang hampir sama dengan mite, hanya legenda lebih mengarah pada proses terjadinya atau asal usul sebuah tempat atau wilayah dalam masyarakat tersebut, misal asal usul terjadinya kota Boyolali. Sedang, dongeng adalah cerita yang lebih banyak bersifat imajinasi suatu kejadian yang penuh khayal yang dalam masyarakat tersebut dianggap tidak benar-benar terjadi, missal dongeng Timun Mas. Bascom [4] menyampaikan bahwa, "cerita rakyat dapat dibagi menjadi tiga yaitu : mite, legenda dan dongeng. Pembagian cerita prosa rakyat ke dalam tiga kategori itu merupakan tipe ideal, karena dalam kenyataannya banyak cerita yang mempunyai ciri lebih dari satu kategori sehingga sulit digolongkan ke dalam salah satu kategori. Cerita-cerita tersebut mengandung nilai-nilai budaya, agama, pendidikan, sosial dan lain-lain." Hal yang membedakan adalah mitos sering dikaitkan dewa-dewa dan atau kekuatan-kekuatan supranatural yang diluar jangkauan manusia.sebaliknya, walu sama-sama menghadiri tokoh-tokoh itu dengan sebaiknya dewa-dewa atau yang berkekuatan suptanatural, melainkan dengan tokoh, peristiwa, atau tempat-tempat nyata yang mempunyai kebenaran sejarah [5].

Cerita rakyat agar tetap hidup, berkembang dan diterima oleh generasi mendatang dilakukan kreaifitas agar cerita rakyat menjadi sebuah karya tulis yang apik. Sangat memungkinkan cerita rakyat dimodifikasi agar bisa diterima oleh masyarakat modern. Hal ini bertujuan agar kesan terhadap cerita rakyat yang kuno bisa dihilangkan dan menjadi cerita rakyat yang menarik. Berbagai hal yang berkaitan dengan cerita rakyat juga bisa dijadikan sebagai media untuk meningkatkan kreatifitas mahasiswa dalam kegiatan menulis kreatif. Cerita rakyat lisan bisa dijadikan objek kajian penelitian atau sebagai bahan menulis kreatif yang akhirnya dapat dikembangkan menjadi bahan ajar atau bisa juga digunakan sebagai bacaan yang menarik untuk masyarakat (buku pengayaan) sekaligus sebagai dokumen pelestarian budaya lokal.

\section{METODE}

Metode yang digunakan dalam kajian ini adalah observasi dan wawancara. Objek kajian pada artikel ini adalah tuturan sastra lisan cerita rakyat .Observasi dilakukan dengan cara melakukan pengamatan langsung pada objek kajian pada waktu tertentu. Observasi dilakukan untuk memperoleh keterangan tentang lingkungan penceritaan dan gambaran sosial masyarakat di daerah tersebut. Hal tersebut sejalan dengan pendapat Arikunto [6] yang menyatakan bahwa observasi adalah mengumpulkan data atau keterangan yang harus dijalankan dengan melakukan usaha-usaha pengamatan secara langsung ke tempat yang akan diselidiki. 


\section{HASIL DAN PEMBAHASAN}

Penelitian ini akan membahas tujuh cerita rakyat yang berkembang di enam kabupaten dan satu kota madya di wilayah Surakarta yaitu, kabupaten Klaten, Boyolali, Sragen, Karanganyar, Sukoharjo, Wonogiri dan kota Solo. Cerita rakyat yang ditampilkan di sini seperti apa yang telah diungkapkan dalam pendahuluan di atas bahwa cerita rakyat yang ada di wilayah Surakarta tidak dapat diidentifikasi secara jelas, apakah itu cerita rakyat legenda, mitos atau dongeng, karena ketiga ciri dari masing-masing jenis itu ada dalam bagian cerita rakyat di daerah tersebut [7]. Dalam cerita legenda atau asal usul sebuah desa atau wilayah, ada satu kepercayaan yang sangat kuat diyakini oleh masyarakat, tokoh utama memiliki kekuatan yang luar biasa yang tidak dimiliki oleh manusia biasa. Kepercayaan itu mengakibatkan tempat tersebut menjadi dikeramatkan, ada pantangan dan kewajiban yang harus ditaati oleh penduduk setempat, apabila dilanggar akan mendatangkan mala petaka. Beberapa cerita rakyat dan pembahasannya tersebut adalah:

\subsection{Bulus Jimbung Wilayah Klaten (legenda, mitos dan fable)}

Cerita rakyat Bulus Jimbung berada di desa Jimbung kecamatan Kalikotes kabupaten Klaten Jawa Tengah. Cerita ini diawali dengan cerita tokoh pendiri desa Jimbung, yaitu Pangeran Patahwan seorang pangeran dari kerajaan Wiratha wilayah Jepara yang mengembara karena dihukum oleh raja Wiratha. Patahwan mengembara sampai di sebuah tempat subur, nyaman, dan indah. Akhirnya Patahwan menetap di tempat itu dan kemudian dinamai tempat itu sebagai desa Jimbung. Dalam perkembangannya, Jimbung menjadi sebuah kerajaan yang makmur gemah ripah loh jinawi dibawah pemerintahan Patahwan dengan bergelar Prabu Jaka. Prabu Jaka terkenal sebagai raja yang gagah, elok parasnya . Kegagahan Prabu Jaka terkenal sampai ke telinga Putri Wahdi atau Putri Keling[8]. Putri Keling menemui prabu Jaka, tetapi cintanya di tolak akhirnya putri Keling nekat bunuh diri. Putri Keling memiliki dua pengasuh yang bernama Poleng dan Remeng. Kedua abdi tersebut marah besar melihat tuan putrinya bunuh diri. Kemarahan Poleng dan Remeng dengan mengobrak abrik desa Jimbung, memancing kemarahan Patahwan, lalu mereka di kutuk Patahwan menjadi bulus. Setelah mereka berdua berubah menjadi bulus, mereka merasa menyesal dan meminta belas kasian kepada Patahwan untuk memberikan sebuah tempat berteduh. Akhirnya Patahwan menancapkan tongkatnya kedalam tanah. Setelah tertancap, tongkatnya di cabut yang mengeluarkan air dan tongkatnya berubah menjadi pohon randu yang besar sekali. Setelah itu Patahwan bersabda agar kedua bulus bertempat tinggal di sendang itu, kelak dikemudian hari banyak orang yang mengunjungi dan memberinya makan.

Sendang itu akhirnya dikenal dengan sebutan Bulus Jimbung, banyak orang berdatangan ke tempat itu. Selain terkenal sebagai tempat pariwisata, Bulus Jimbung di kenal sebagai tempat untuk mencari kekayaan dengan istilah mencari pesugihan, yaitu mencari kekayaan dengan bantuan mahkluk gaib (bulus putih).

\subsection{Desa Butuh Wilayah Sragen (legenda)}

Desa Butuh terletak di kecamatan Plupuh kabupaten Sragen. Cerita rakyat ini mengisahkan asal usul berdirinya desa Butuh. Cerita Desa Butuh tidak lepas dari kisah Ki Kebo Kenanga seorang pejabat tinggi kerajaan Demak yang diberi kekuasaan di wilayah Pengging. Kebo Kenongo merupakan seseorang yang sholeh, baik hati, dan selalu mendekatkan diri kepada Yang 
Maha Kuasa. Ia menjadi adipati yang sangat disayangi oleh rakyatnya. Pada suatu hari, Ki Kebo Kenongo mendapat semacam perintah untuk menghadap sang Raja Demak. Terjadi kesalahpahaman perintah mengakibatkan Kebo Kenanga tidak datang. Ketidakhadiran ini mengakibatkan Raja Demak tersinggung, menganggap Kebo Kenanga memberontak. Atas nasihat Sunan Kudus, agar tidak terjadi pertumpahan darah, Kebo Kenanga disarankan menyepi di sebuah tempat yang tidak diketahui prajurit kerajaan Demak. Sampailah Kebo Kenanga dan istri di sebuah desa, yang dinamainya desa Butuh, beliau di kenal dengan sebutan Ki Ageng Butuh. Beliau menetap di desa itu sampai meninggal dunia dan dimakamkan di desa ini pula.

Ki Kebo Kenangan, memiliki seorang anak yang bernama Mas Karebet yang selanjutnya lebih dikenal dengan nama Jaka Tingkir. Jaka Tingkir tumbuh menjadi pribadi yang cerdas, kuat dan rendah hati. Karena kepiawaian dan kecerdasannya tersebut, ia diangkat menjadi Sultan Demak yang ke-4 menggantikan Sultan Trenggono atas persetujuan para orang tua, wali dan leluhur yang ada di sana. Namun, karena kondisi di sana yang kurang kondusif, Raden Jaka Tingkir akhirnya memindahkan ibukota kerajaannya ke daerah Pajang (Surakarta) dan menjadi Sultan Pajang. Setelah bertahun-tahun mengabdikan dirinya sebagai raja, pada masa tuanya Raden Jaka Tingkir lebih memilih untuk mendekatkan diri kepada Sang Pencipta. Ia pun pergi ke dusun tempat orang tuanya mengasingkan diri dulu. Ia mengunjungi makam orang tuanya (Ki Kebo Kenongo) dan menetap di sana hingga ia meninggal dunia. Setelah itu, ia pun dimakamkan satu kompleks dengan makam orang tuanya, sehingga oleh masyarakat kompleks makam tersebut diberi nama Makam Jaka Tingkir.

\subsection{Sapta Tirta Wilayah Matesih Karanganyar (mitos)}

Sapta Tirta Pablengan terletak di Jalan bukit Argotiloso, Desa Pablengan, Kecamatan Matesih, Kabupaten Karanganyar. Sapta Tirta Pablengan merupakan tempat wisata bersejarah peninggalan masa kerajaan Mangkunegara VI Surakarta. Nama Sapta Tirta Pablengan diambil karena di tempat ini terdapat tujuh mata air, sapta yang bermakna tujuh, tirta yang bermakna air dan Pablengan merupakan nama dari desa tempat munculnya sumber air tersebut.

Pada masa kerajaan sumber mata air ini digunakan sebagai kekuatan para prajurit Raden Mas Said yang akan perang. Letak ketujuh mata air ini saling berdekatan dan memiliki nama yang berbeda-beda sesuai dengan fungsinya. Sumber air pertama yakni air Bleng, bertujuan untuk membulatkan tekad (ngeblengake) dan menyatukan cipta, rasa, serta karsa. Sementara di tempat mandi kedua, di air Urus-urus, memiliki makna filosofi agar tujuan beliau mengusir penjajah dapat terurus atau tercapai.

Tempat mandi ketiga, di air Soda, bertujuan agar memperoleh kesegaran jasmani dan tidak kelelahan saat perang gerilnya. Di tempat mandi keempat dan kelima, yakni di air mati dan air hidup (panguripan) bertujuan mengingatkan bahwa hidup dan mati dalam peperangan harus diserahkan kepada Tuhan. Kemudian di tempat mandi keenam, di air Kasekten, memiliki makna agar pasukan Raden Mas Said mendapatkan kekuatan secara batiniah untuk tak lelah melawan penjajah. Adapun di tempat mandi terakhir atau ketujuh, di sumber air hangat Kamulyan, bertujuan agar segala tujuan mendapatkan ketenteraman, kedamaian, dan kemakmuran. 


\subsection{Asal usul berdirinya Balaikambang Wilayah Solo (Legenda dan dongeng)}

Pada masa itu, KGPAA Mangkunegara VII, salah satu penguasa Karesidenan Surakarta Hadiningrat mendirikan sebuah tempat perlindungan untuk melindungi rakyat Jawa dari serangan musuh. Usaha perlindungan yang dilakukan oleh KGPAA Mangkunegara VII dibantu oleh dua putri kesayangan raja, GRAy Partini Husein dan GRAy Partinah Sukanta. Kedua putri KGPAA Mangkunegara

Surakarta saat itu menjadi kerajaan yang damai, aman dan makmur. Sampai pada suatu hari, datangalah dua raksasa yang bernama Buta Balegong dan Buta Adikambang. Mereka berniat menghancurkan kedamaian kerajaan. Balegong dan Adikambang menyamar sebagai tenaga perbaikan keraton, tetapi samaran mereka diketahui oleh kedua putri raja, yaitu Gusti Partinah dan Gusti Partini. Dua putri itu pula dengan kekuatannya mampu mengalahkan kedua raksasa tersebut. Tempat pertempuran itulah yang sekarang diberi nama Bale Kambang, yaitu di ambil nama dari dua raksasa tersebut. Untuk meengenang kehebatan kedua putrinya, KGPAA Manngkunegaran VII membuat patung Gusti Partini dan Partinah di Bale Kambang tersebut.

\subsection{Alas Donoloyo Wilayah Wonogiri (Mitos dan dongeng)}

Hutan Donoloyo atau biasa yang disebut dengan Alas Donoloyo merupakan hutan cagar alam yang berlokasi di Desa Sambirejo dan Desa Watusumo Kecamatan Slogohimo Kabupaten Wonogiri Jawa Tengah. Hutan ini di dominasi dengan pohon jatinya dengan luas kurang lebih 8 hektare. Beberapa usia pohon jati di sini ada yang berusia sekitar 500-700 tahun. Kayu jati yang berasal dari alas ini terkenal memiliki kualitas kayu terbaik sampai saat ini. Memiliki rata-rata panjang 10 meter dengan garis tengah satu meter.

Masjid Demak dan Istana keraton Surakarta banyak mengambil kayu jati dari tempat ini. Cara pengiriman kayu jati ke Demak dan keraton Surakarta yang tidak wajar pada zaman itu, menjadi cerita dongeng tersendiri [9]. Diceritakan dengan kesaktiannya, Ki Ageng Donoloyo membungkus atau menutup kayu tersebut dengan kain, dan melarungnya di sungai. Kayu itu tidak terlihat oleh manusia. Kayu akan menepi dengan sendirinya, dan kayu tersebut baru akan terlihat oleh manusia ketika sampai ditepi sungai yang dituju.

Cerita Alas Donoloyo diawali dari kisah dua kakak beradik Ki Ageng Donoloyo dan Ki Agung Sukoboyo (saudara ipar) yang diutus raja Majapahit mencari wilayah yang subur, untuk dibuka menjadi daerah baru. Dalam pengembaraannya, sampailah kakak beradik itu di sebuah daerah yang gersang Di tempat itu mereka berpisah, Ki Donoloyo berhenti di tempat tersebut, sedang Ki Sukoboyo tingga di sebelah baratnya. Daerah yg dihuni ki Donoloyo tetap menjadi desa yang gersang, semua tumbuhan yang ditanam tidak ada yang hidup. Semua layu dan mati beberapa hari kemudian. Sedang, daerah yang dihuni kakak dan kakak iparnya menjadi daerah yang subur, semua tanaman tumbuh dengan suburnya.

Sampai pada suatu saat, Ki Donoloyo mendatangi kakak ipar untuk minta bibit, tetapi kakak ipar tidak mau memberi karena dalam hati kecil dia takut kalah bersaing. Kalau Ki Donoloyo diberi bibit tanaman, pastilah hasil tanaman akan lebih baik darinya sehingga dia takut tidak mendapat pujian dari Raja ketika bertandang ke wilayahnya. Pulangnya Ki Donoloyo dengan sedihnya. Dalam perjalanan pulang, Ki Donoloyo dihadang kakak perempuannya (istri Ki Sukoboyo) karena tidak sampai hati melihat adiknya bersedih, dengan sembunyi-sembunyi sang kakak membawakan beberapa bibit biji pohon jati untuk adik kesayangannya. 
Ki Ageng Donoloyo sangat berterima kasih dengan Mbak Ayunya, ia berjanji akan menanam dan merawat bibit jati ini. Lekas ia berpamitan kembali dan tidak lupa pelukan hangat untuk saudara sekadungnya itu.Selama perjalanan pulang yang melelahkan ia berteduh di bawah pohon beringin. Mengistirahatkan tubuhnya yang lelah. Namun tanpa sepengetahuanya, satu bibit jati dari bungkusan itu terjatuh di sekitar pohon beringin dan ia tetap melanjutkan perjalanan pulang. Konon katanya, bibit jati yang tumbuh itu diberi nama Jati Denok[10].

Dalam kurun beberapa waktu jati yang dibawakan Mbak Ayunya berhasil tumbuh. Ki Ageng Donoloyo sangat senang bukan main. Semakin lama pohon jati di hutan itu semakin banyak dan tumbuh subur. Warga desa pun sangat antusias menjaga kelestarian jati-jati di sana. Bibit jati yang diberikan Mbak Ayu tumbuh menjadi pohon jati yang snagat besar dan kuat, Ki Ageng Donoloyo memberinya nama Jati Cempurung.

Mengetahui adik iparnya yang memiliki hutan jati yang luas dan subur, Ki Ageng Sukoboyo menaruh curiga. Ia pun sangat murka ketika mengetahui bahwa Istrinya sendiri yang memberikan bibit jati itu kepada Ki Ageng Donoloyo. Ki Sukoboyo tidak bisa memaafkan perbuatan kakak beradik itu, ia mengutuk kedua kakak beradik itu tidak pernah lagi bisa ketemu, akan berpisah selamanya dan tidak akan ada perkawinan antara dua daerah itu.

\subsection{Makam Sawungrono Wilayah Boyolali (Mitos)}

Di Desa Wates, Kecamatan Klego, Boyolali, terdapat sebuah makam yang diberi nama makan Sawungrono. Diceritakan bahwa dulu ada seorang pendekar bernama Sawungrono, Sawung sendiri dalam bahasa jawa memiliki arti ayam jantan atau orang yang diajukan sebagai calon dalam pemilihan [11]. Sawungrono sendiri selain sakti juga memiliki budi yang luhur. Menjadi ksatria membuatnya harus siap menghadapi perkelahian hingga perang membela kerajaanya.

Sawungrono menjadi teladan masyarakat sekitar dalam mendidik anak mereka agar bisa memiliki budi luhur dan kesaktian seperti dia. Banyak orang mengelu-elukan segala kelebihan dari Sawungrono. Bahkan tidak sedikit yang berusaha keras agar bisa menjadi murid dari Sawungrono. Namun sayang, saat terjadi perang antar kerajaan yang mengharuskan Sawungrono bertarung, dia gugur dan akhirnya hilang, setelah ditemukan, Sawungrono lalu dimakamkan di sebuah tempat. Kemudian tempat itu menjadi sebuah pemakaman yang diberi makam Sawungrono. Makam Sawungrono sampai sekarang masih sering dikunjungi masyarakat untuk mendapatkan berkah.

Demikianlah bahwa banyak cerita rakyat yang ada di Indonesia dapat dijadikan materi ajar untuk pembelajaran BIPA. Tujuan menggunakan cerita rakyat ini tentunya lebih mempermudah mengenal bahasa dan budaya Indonesia dan membantu mengenal budaya Indonesia secara lebih dekat [12][13].

\section{SIMPULAN}

Tujuh cerita rakyat yang disampaikan di atas memiliki jenis yang berbeda, hanya dalam penceritaannya, bercampur dan tidak terpisahkan antara legenda, mitos dan dongeng. Sehingga penulis menyebutnya sebagai cerita rakyat (folklore). Masing-masing cerita memiliki anamat yang hampir sama, yaitu mengandung unsur nilai karakter, nilai pendidikan dan nilai sosial. Cerita rakyat yang semula berbentuk sastra lisan menjadi sastra ditulis, memiliki manfaat : (1) sebagai bahan pembelajaran siswa semua jenjang pendidikan, (2) sebagai buku teks mahasiswa Pendidikan 
Bahasa Indonesia, khususnya dalam mata kuliah menulis kreatif, (3) sebagai bahan pembelajaran BIPA, (4) buku pengayaan budaya daerah setempat, (5) pelestarian budaya nusantara dalam bidang sastra.

Dari kegiatan menulis cerita berbasis muatan lokal cerita rakyat, mahasiswa dapat menghargai dan mengetahui kekayaan budaya bangsa, yaitu cerita rakyat nusantara. Selain itu, menulis kreatif dapat melatih mahasiswa untuk melakukan pembelajaran mandiri, menemukan sumber materi menulis melalui observasi dan wawancara. Selain itu, mahasiswa juga dapat memaksimalkan kemampuan menulisnya dengan membuat kreatifitas yang berbeda sebagai ujud menjadi seorang mahasiswa yang kreatif, juga bagian dari pelestarian budaya nusantara agar tidak punah atau hilang dari bumi Indonesia.

\section{REFERENCES}

[1] P. Chatterjee, D. Mishra, L. K. Padhi, J. Ojha, A. A. Al-Absi, and M. Sain, "Digital StoryTelling: A Methodology of Web Based Learning of Teaching of Folklore Studies," in 201921 st International Conference on Advanced Communication Technology (ICACT), 2019, pp. 573-578.

[2] J. Danandjaja, Folklor Indonesia: ilmu gosip, dongeng, dan lain lain. Grafiti Pers, 2007.

[3] D. M. Barone, Children's literature in the classroom: Engaging lifelong readers. Guilford Press, 2010.

[4] J. Danandjaja, Folklor Jepang: dilihat dari kacamata Indonesia. Pustaka Utama Grafiti, 1997.

[5] B. W. Setyawan and K. Saddhono, "Eret traditional ceremony as representation of spirit of mutual cooperation among coastal communities," Adv. Sci. Lett., vol. 23, no. 10, 2017.

[6] B. Nurgiyantoro, "Penggunaan Ungkapan Jawa dalam Kumpulan Puisi Tirta Kamandanu karya Linus Suryadi (Pendekatan Stilistika Kultural)," LITERA, vol. 13, no. 2, 2014.

[7] R. Baron, "Public Folklore: Theory of/in Practice (A response to elliott oring)," J. Am. Folk., vol. 132, no. 524, pp. 163-174, 2019.

[8] D. Pusposari, D. Saryono, W. Siswanto, and M. Hasanah, "Ande-Ande Lumut Folklore as the Builder of Youth Character," 2019.

[9] H. Erwinsyah, "Animation-Based Legendary Stories Materials from Banjarnegara to Teach Javanese in Junior High School," in Journal of Physics: Conference Series, 2019, vol. 1339 , no. 1 , p. 12119.

[10] K. Saddhono and D. Pramestuti, "Sekar Macapat Pocung: Study of Religious Values based on The Local Wisdom of Javanese Culture," El Harakah, vol. 20, no. 1, p. 15, 2018.

[11] U. Chafidhi, W. Abdullah, and D. Purnanto, "Local Wisdom in Javanese Language and Culture expressed by the Javanese Coastal Community of Banjar Kemuning Village of Sidoarjo (An Ethnolinguistic Study)," in Fifth Prasasti International Seminar on Linguistics (PRASASTI 2019), 2019.

[12] Saddhono, K., \& Erwinsyah, H. Folklore As Local Wisdom for Teaching Materialsin Bipa Program (Indonesian for Foreign Speakers). KnE Social Sciences, pp.444-454. 2018.

[13] K. Saddhono, "Integrating culture in Indonesian language learning for foreign speakers at Indonesian universities," J. Lang. Lit., vol. 6, no. 2, 2015. 
